\title{
LIDAR DERIVED FINE SCALE RESOLUTION PROPERTIES OF TROPOSPHERIC AEROSOL MIXTURES
}

\author{
Lucja Janicka $^{1}$, Christine Böckmann ${ }^{2}$, Iwona S. Stachlewska ${ }^{1}{ }^{*}$, Dongxiang Wang ${ }^{1}$ \\ ${ }^{1}$ University of Warsaw, Faculty of Physics, 02-093 Warsaw, Poland \\ ${ }^{2}$ University of Potsdam, Institute of Mathematics, D-14476 Potsdam, Germany \\ *Email: iwona.stachlewska@fuw.edu.pl
}

\begin{abstract}
Fine scale resolution analysis was applied to the complicated aerosol structures observed with the PollyXT-UW lidar over Warsaw during the night of $9 / 10$ August 2015. The full sets of the particle optical properties profiles, so called $3 \beta+2 \alpha+2 \delta+w v$ (3 backscattering, 2 extinction coefficients, 2 depolarization ratios and water vapour mixing ratio), were obtained to discriminate multiple aerosol height sectors, which were then used for the microphysical properties inversion. The statistical characterization of the main aerosol/mixture types was obtained.
\end{abstract}

\section{INTRODUCTION}

For studies on influence of atmospheric aerosol on the earth radiative budget it is crucial to know the optical and microphysical properties of aerosol particles related to particular aerosol type, the altitude of aerosol layers suspension, and the type of ground surface over which the layers are present. Additional challenge arises, when suspended aerosol does not represent pure aerosol type, but composes a mixture of different ones. Exploration of the aerosol mixtures properties is a difficult task and requires detailed analysis in the fine scale.

The presented study concerns multiple aerosol layers detected over Warsaw during a heat wave event over Poland, known as favoring the longrange transport of biomass burning aerosol [1]. Biomass burning particles advection (2-3 days old) from over France, Germany, and Czech Republic, was observed in majority of the layers over Warsaw, being sometimes mixed in with an anthropogenic pollution from sources in Poland [2].

\section{METHODOLOGY}

In the current study, the data from the 8-channel PollyXT-UW lidar [3], installed at the Remote Sensing Laboratory (RS-Lab) of the Institute of Geophysics, Faculty of Physics, University of Warsaw $\left(52.21^{\circ} \mathrm{N}, 20.98^{\circ} \mathrm{E}, 112 \mathrm{~m}\right.$ a.s.l) were analyzed. The RS-Lab operates within the European Aerosol Lidar Network EARLINET [4]. The quasi-continuous vertical lidar measurements with the 355, 532, $1064 \mathrm{~nm}$ laser light, provide the elastic backscattering signals at all three emitted wavelengths, the elastic depolarized signals at 355 and $532 \mathrm{~nm}$, the non-elastic Raman signals on $\mathrm{N}_{2}$ molecules at 387 and $607 \mathrm{~nm}$ and on $\mathrm{H}_{2} \mathrm{O}$ at 407 $\mathrm{nm}$. The raw signal resolution is $30 \mathrm{~s}$ and $7.5 \mathrm{~m}$.

The sets of the particle optical properties profiles $(3 \beta+2 \alpha+2 \delta+\mathrm{wv})$ are derived using the classical Raman approach, according to the evaluation scheme given in [5], and then smoothed using a customized algorithm detailed in [2]. The profiles of linear particle depolarization ratio were derived with the $\pm 45^{\circ}$ calibration method [3]. The relative humidity profiles were derived as in [6].

The microphysical properties (complex refractive index $(\mathrm{m})$, particle size distribution, effective radius ( $\mathrm{R}_{\text {eff }}$, surface $(\mathrm{S})$ and volume (V) concentrations) were obtained using the inversion algorithm developed at University of Potsdam; details are given in [7],[8],[9]. For all calculations the spherical model was used, as the mineral dust contribution was not expected. The regularization method based on the truncated singular value decomposition (TSVD) was applied.

The optical properties were calculated for each consecutive 30 minutes from 19-02 UTC on the night of 9/10 August 2015. In total 9 sets of $3 \alpha+2 \beta+2 \delta+w v$ profiles were obtained. In each set, multiple height sectors were discerned; based mainly on the extinction and relative humidity profiles. The mean values of optical properties 
were obtained in each height sector, and based on those the intensive aerosol properties calculation and microphysical inversion followed. Finally, the height sectors were grouped in the main aerosol/mixture layers and the optical properties within them were obtained in a statistical way. Extensive analysis of the results is given in [2].

\section{RESULTS}

\subsection{Optical properties}

Fine scale analysis of optical properties derived in all height sectors (for brevity only some are indicated in Fig.1) allows for discrimination of the same aerosol type layers in statistical way. In lowermost Layer 1 (Fig.1, in black), anthropogenic industry-driven pollution uplifted from boundary layer was likely mixed with biomass burning. Here the lidar ratios are being relatively low: $\mathrm{LR}_{355}$ of $55 \pm 6 \mathrm{sr}$ and $\mathrm{LR}_{532}$ of $43 \pm 4$ sr with Ångström exponent $\mathrm{AE}_{\alpha}$ of $1.48 \pm 0.10$. Above it, Layer 2 contained moderately-fresh biomass burning aerosol. Here the lidar ratios were significantly higher with the mean values of $76 \pm 7 \mathrm{sr}$ for $\mathrm{LR}_{355}$ and $62 \pm 4 \mathrm{sr}$ for $\mathrm{LR}_{532}$. The $\mathrm{AE}_{\alpha}$ of $1.35 \pm 0.18$ was only slightly lower. For both layers, the particle depolarization ratios were similar at each wavelength: $\delta_{355}$ of $1.5-1.6 \%$ and $\delta_{532}$ of $3.5-3.6 \%$.

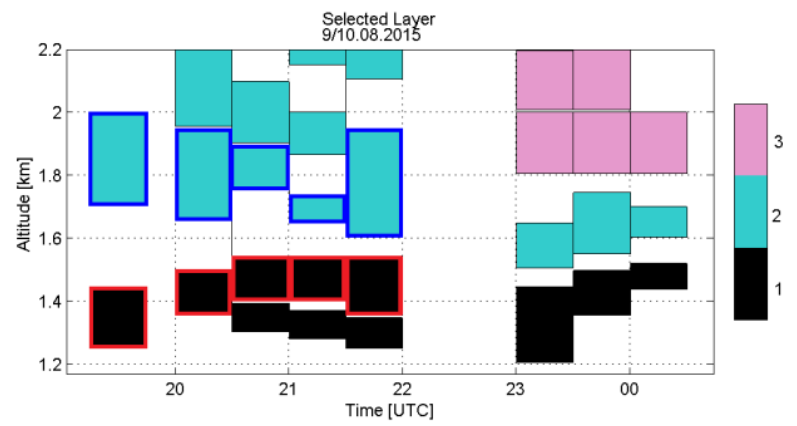

Figure 1: Schematic plot of aerosol layers derived on the night of 9/10 August 2016 from PollyXT-UW at the EARLINET-ACTRIS lidar site in Warsaw. Each color depicts different aerosol type. Blue and red rectangles mark layers for which microphysical inversion results are shown in Fig 2.

\subsection{Microphysical properties}

The microphysical properties derived in height sectors marked by red and blue rectangles in Fig.1, reveal very good agreement of the obtained results. The particle size distributions (Fig.2) have a fine mode dominating $(\sim 0.12 \mu \mathrm{m})$ and much smaller modes at larger radii $(\sim 0.75$ and $\sim 1.5 \mu \mathrm{m})$. This consistency is clear in reference to individual height sectors and the mean values of each layer type, whereby the mean distributions for the biomass burning aerosol (Layer 2) and the anthropogenic pollution (Layer 1) differ only in terms of the $0.75 \mu \mathrm{m}$ mode existing in the latter.

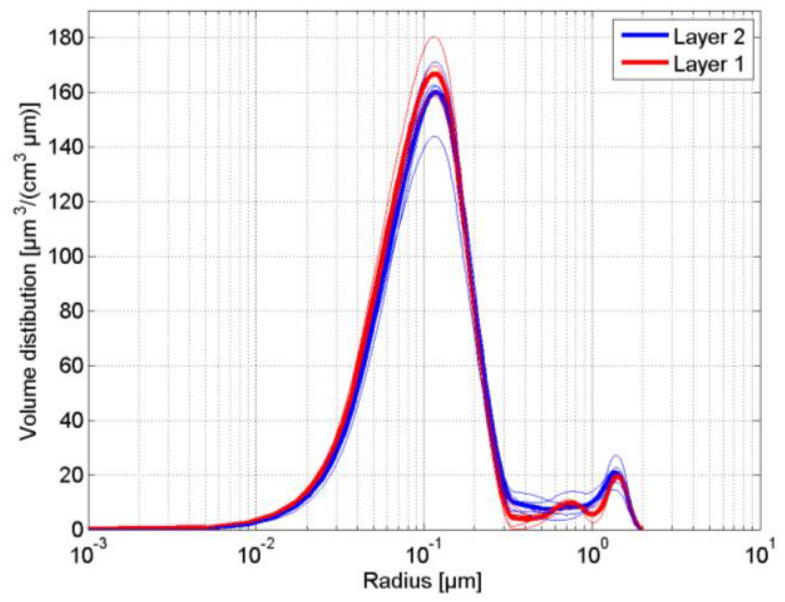

Figure 2: Particle size distributions obtained by the microphysical inversion of the PollyXT-UW lidar data at the night of 9/10 August 2016 at in Warsaw. Thin lines denote individual distributions for each height sector and the thick lines the mean distributions for each aerosol-type layer .

Table 1: Mean microphysical properties for aerosol layers derived in height sectors, depicted in rectangles in Fig. 1, with the standard deviation.

\begin{tabular}{|c|c|c|c|c|c|c|}
\hline $\begin{array}{c}\mathrm{R}_{\mathrm{eff}} \\
{[\mu \mathrm{m}]}\end{array}$ & $\begin{array}{c}R e \\
\mathrm{~m}\end{array}$ & $\begin{array}{c}I m \\
\mathrm{~m}\end{array}$ & $\begin{array}{c}\mathrm{S} \\
{\left[\mu \mathrm{m}^{2}\right.} \\
\left./ \mathrm{cm}^{3}\right]\end{array}$ & $\begin{array}{c}\mathrm{V} \\
{\left[\mu \mathrm{m}^{2}\right.} \\
\left./ \mathrm{cm}^{3}\right]\end{array}$ & $\mathrm{SSA}_{355}$ & $\mathrm{SSA}_{532}$ \\
\hline \multicolumn{7}{|c|}{ Layer 1 mixed BB \& AP } \\
\hline $\begin{array}{c}0.15 \\
\pm \\
0.01\end{array}$ & $\begin{array}{c}1.54 \\
\pm \\
0.01\end{array}$ & $\begin{array}{c}0.013 \\
\pm \\
0.002\end{array}$ & $\begin{array}{c}783 \\
\pm \\
34\end{array}$ & $\begin{array}{c}40 \\
\pm \\
2\end{array}$ & $\begin{array}{c}0.92 \\
\pm \\
0.01\end{array}$ & $\begin{array}{c}0.90 \\
\pm \\
0.01\end{array}$ \\
\hline \multicolumn{7}{|c|}{ Layer 2 long-range transported BB } \\
\hline $\begin{array}{c}0.17 \\
\pm \\
0.02\end{array}$ & $\begin{array}{c}1.55 \\
\pm \\
0.02\end{array}$ & $\begin{array}{c}0.028 \\
\pm \\
0.003\end{array}$ & $\begin{array}{c}757 \\
\pm \\
52\end{array}$ & $\begin{array}{c}43 \\
\pm \\
5\end{array}$ & $\begin{array}{c}0.85 \\
\pm \\
0.02\end{array}$ & $\begin{array}{c}0.83 \\
\pm \\
0.02\end{array}$ \\
\hline
\end{tabular}


In Table 1, the mean microphysical properties for each aerosol layer are listed. The effective radius $\mathrm{R}_{\mathrm{eff}}$, the volume $\mathrm{V}$ and surface $\mathrm{S}$ concentrations are the same in the standard deviation limit. The real part of refractive index is also similar for both aerosol types. However, the imaginary part of $0.013 \pm 0.01$ (Layer 1) and $0.028 \pm 0.02$ (Layer 2) differ distinctly, indicating higher absorption for the biomass burning layer. The single scattering albedo (SSA) for this layer is very low $\sim 0.84$, as expected. In the anthropogenic pollution layer the SSA is of $\sim 0.91$, which is still indicating possible absorption, thus pollution mixed with biomass burning is confirmed.

\section{CONCLUSIONS}

In presented study, optical and microphysical properties of aerosol over Warsaw during a heat wave event were derived and analyzed in fine temporal and spatial scales. The analysis allowed for discrimination of aerosol layers dominated by the long-range transported biomass burning (lidar ratios higher than $\sim 20 \mathrm{sr}$, twice higher imaginary part of the refractive index) and those being mixed with the anthropogenic pollution (additional mode at radius of $\sim 0.75$, higher SSA). This case study has a great potential for further use in aerosol type separation algorithms.

\section{ACKNOWLEDGEMENTS}

The PollyXT-UW lidar was developed within R\&D collaboration of the University of Warsaw and the Leibniz Institute of Tropospheric Research (TROPOS), in the PollyXT development group of Dietrich Althausen. This development was financed by the Polish Foundation of Science and Technology (519/FNITP/115/2010).

The RS-Lab site provides the data products to the PolandAOD-NET (http://www.polandaod.pl), the EARLINET (https://www.earlinet.org), and the Polly.NET (http://polly.tropos.de) networks.

The algorithms used for lidar data evaluation were developed in the frame of ESA-ESTEC Contract 4000112373/14/NL/CT (MULTIPLY).

The EARLINET is supported by the ACTRIS-2 project, funded by the European Union Research
Infrastructure Action under the H2020 specific program for Integrating and opening existing national and regional research infrastructures of European interest under Grant Agreement No. 654109 and No. 739530. The University of Warsaw and the University of Potsdam participate in ACTRIS-2 project as an associate partner without funding.

\section{REFERENCES}

[1] I. S. Stachlewska, et al.: Modification of local urban aerosol properties by long-range transport of biomass burning aerosol, Rem. Sens., 10, 412, doi:10.3390/rs10030412 (2018)

[2] L. Janicka, and I. S. Stachlewska: Properties of biomass burning aerosol mixtures derived at fine temporal and spatial scales from Raman lidar measurements: Part I optical properties, Atmos. Chem. Phys. Discuss. (2019)

[3] R. Engelmann, et al.: The automated multiwavelength Raman polarization and water-vapor lidar PollyXT: The next generation, Atmos. Meas. Tech., 9, 1767-1784, doi:10.5194/amt-9-1767-2016 (2016)

[4] G. Pappalardo, et al.: EARLINET: Towards an advanced sustainable European aerosol lidar network, Atmos. Meas. Tech., 7, 2389-2409, doi: 10.5194/amt7-2389-2014 (2014)

[5] H. Baars, et al.: An overview of the first decade of Polly NET: An emerging network of automated Raman-polarization lidars for continuous aerosol profiling, Atmos. Chem. Phys., 16, 5111-5137, doi:10.5194/acp16-5111-2016 (2016)

[6] I. S. Stachlewska, et al.: Raman lidar water vapour profiling over Warsaw, Poland, Atmos. Res., 194, 258267, doi:10.1016/j.atmosres.2017.05.004 (2017)

[7] C. Böckmann, et al.: Microphysical aerosol parameters from multiwavelength lidar, J. Opt. Soc. Am. A, 22(3), 518-528, doi:10.1364/JOSAA.22.000518 (2005)

[8] S. Samaras, et al.: Using Raman-lidar-based regularized microphysical retrievals and Aerosol Mass Spectrometer measurements for the characterization of biomass burning aerosols, J. Comput. Phys., 299, 156174, doi:10.1016/j.jcp.2015.06.045 (2015)

[9] D. Müller, et al.: Microphysical particle properties derived from inversion algorithms developed in the framework of EARLINET, Atmos. Meas. Tech., 9, 5007-5035, doi:10.5194/amt-9-5007-2016 (2016) 